\title{
Electrodeposition of A Novel Pd-Ni-W Ternary Alloy Film on SS316L
}

\author{
Zhiheng Zhang ${ }^{1}$, Junlei Tang ${ }^{1, *}$, Yingying Wang ${ }^{1}$, Mihai Apreutesei $^{2}$, Hu Wang $^{3}$ \\ ${ }^{1}$ School of Chemistry and Chemical Engineering, Southwest Petroleum University, Chengdu 610500, \\ China \\ ${ }^{2}$ Université de Lyon, Institut des Nanotechnologies de Lyon INL-UMR5270, CNRS, Ecole Centrale \\ de Lyon, Ecully F-69134, France \\ ${ }^{3}$ School of Material Science and Engineering, Southwest Petroleum University, Chengdu 610500, \\ China \\ *E-mail: tangjunlei@126.com
}

doi: $10.20964 / 2017.07 .39$

Received: 26 February 2017 / Accepted: 19 April 2017 / Published: 12 June 2017

Pd-Ni-W ternary alloy films were electrodeposited on 316L stainless steel. Electrolytes containing different contents $(5-40 \mathrm{~g} / \mathrm{L})$ of $\mathrm{Na}_{2} \mathrm{WO}_{4}{ }^{2-}$ were used. Effects of concentration of tungsten on film structure, morphology, composition, micro-hardness and corrosion resistance were studied. The addition of tungsten refined crystalline grain and promoted hardness effectively. Electrochemical results showed that with proper tungsten in electrolytic bath, obtained film had reinforced corrosion resistance in hot sulphuric acid solution.

Keywords: Electrodeposition, Pd-Ni-W film, Corrosion

\section{FULL TEXT}

(C) 2017 The Authors. Published by ESG (www.electrochemsci.org). This article is an open access article distributed under the terms and conditions of the Creative Commons Attribution license (http://creativecommons.org/licenses/by/4.0/). 